urine, appears to be round about 1 , and not exceeding 1.4 in normal health, but considerably increased in various abnormal states of metabolism. At an early stage in our investigation we came across an interesting example of the phenomenon we define as acidosis.

In one healthy adult male the average value for $R$, determined with early morning specimens, was 1.14 (maximum, 1.35 ; minimum, 0.88). After he had taken 10 grains of aspirin on the previous night the following values for $R$ were obtained: 8 a.m., $1.96 ; 11$ a.m., $1.47 ; 3$ p.m., 1.05 .

It should be noted that the acidity titratable with standard alkali was diminished rather than increased, but the ammoniacombined acid greatly increased. As described in the papers referred to, we were able to determine the ratio $\mathrm{R}$-later referred to in our work as $R_{A}$-in health and disease.

\section{Its Practical Application}

A paper published in $1928^{7}$ contained further notes on the subject. We examined a number of urines where acidosis existed in association with ketosis, and also urines in which one of the conditions was present without the other.

One case was that of a little girl, who was the subject of cyclic vomiting, the attacks of vomiting being initiated by: various causes - for example, an attack followed an accidental blow with a spade on one occasion; on another occasion an attack supervened after a prolonged railway journey, and in other instances dietetic errors seemed to produce the vomiting and other symptoms.

In health the average value of $\mathrm{R}$ for early morning specimens of urine was 1.07 , and during one attack on successive days this ratio was $1.8,2.95$, and 3.45 , acetone bodies being also present. During another attack acetone bodies were present with a normal ratio-absence of acidosis-whereas at the end of the attack there was marked acidosis $(R=3.25)$, but no ketosis.

In a case of diabetes which terminated fatally $R_{A}$ varied from 1.82 to 3.6, acetone bodies and sugar being also present. In one case of tuberculous meningitis acetone bodies were present, $R_{A}$ being 3 .

\section{We submit:}

\section{Summary}

1. That the term " acidosis" is a very convenient one, and should be used to denote a biochemical phenomenon, in which the normal tendency of the body to form acid products of metabolism is enhanced ; and that the phenomenon is exactly comparable with such phenomena as elevated temperature, accelerated pulse, and various rashes which may form integral parts of quite distinct symptom-complexes. This definition postulates that there can be no "types" of acidosis.

2. That in acidosis the accumulation of acids in the blood is prevented by compensatory mechanisms. When these mechanisms fail acidaemia supervenes.

3. That the detection of acidosis by quantitative analysis of the early morning urine may furnish a valuable sign, and help in the construction of a definite disease syndrome.

\section{REFERENCES}

${ }^{1}$ Halliburton and McDowall: Handbook of Physiology, 1933.

${ }^{2}$ Samson Wright: Applied Physiology, 1926.

3 Wells: Chemical Pathology, Fourth Edition, p. 557.

4 Clinical Journal, February 11th and 18th, 1925.

5 British Medical Journal, 1923, ii, 21.

Ibid., 1927, i, 758.

7 Archives of Disease in Childhood, February, 1928.

The Ministry of Health has issued in pamphlet form (H.M. Stationery Office ; price 6d.) a revised list of sanatoria and other residential institutions approved by the Minister for the treatment of persons suffering from tuberculosis and resident in England and Wales, with the names of the administrative counties and county boroughs in which the institutions are situate.

\section{MONILETHRIX \\ A SECOND GROUP OF FAMILIAL CASES \\ BY}

J. GOODWIN TOMKINSON, M.D.

HONORARY CONSULTING PHYSICIAN, SKIN DEPARTMENT, WESTERN LNFIRMARY, GLASGOW ; DERMATOLOGIST, EDUCATION HEALTH SERVICE, HEALTH DEPARTMENT, GLASGOW ; AND EDUCATION AUTHORITY, COUNTY OF DUMBARTON

In the Section of Dermatology of the Centenary Meeting of the British Medical Association, held in London in July, 1932, I read a paper on this condition based on twenty-two familial cases occurring in five generations in a mining district about eight miles east of Glasgow.*

On August 24th, 1933, I saw, in the Western Infirmary, Glasgow, a girl aged 8 years sent by Dr. W. H. Howat of Dalmellington, Ayrshire. She had just come under his care, and the condition for which she sought relief had previously been diagnosed as ringworm of the scalp.

\section{First Case}

On examination there was no mistaking the affection of the girl's scalp. The short hairs, some twisted, and exhibiting nodes, so distinct that careful inspection revealed them to the unaided eye, associated with the usual accompaniment of lichen pilaris (especially evident suboccipitally), presented an unmistakable picture of monilethrix. According to her mother lichen pilaris had been present from birth, and the hair had been abnormally short in infancy.

\section{Her Family}

I examined three other affected members of the family on February 3rd, 1934-namely, the mother herself and two boys, one aged 13 years, the other aged 3 years. In all, four persons are affected.

As regards the older boy, his mother said that the hair of the scalp up to the age of 9 or 10 years was very short at the back, but then began to grow somewhat better. This resembles, to some extent, the history of one of the group of twenty-two cases reported at the Centenary Meetingnamely, a youth whose hair at the age of 14 years showed signs of improved growth which, being coincident with puberty, might have been due to increased activity of the sebaceous glands. It is not improbable that the mother's statement as to age of improvement in hair growth of the boy now reported was not absolutely accurate, and that the improvement occurred when he was somewhat older. In his case she thought that the lichen pilaris began at about the age of 3 years. It was quite pronounced on the nape and occiput at the time of inspection.

The younger boy showed signs of the affection when a year old, and he has (November, 1934) well-marked lichen pilaris of the nape.

The mother, aged 32, stated that in her own case there was no improvement in growth with the advent of puberty, and that at one time " pimples" (? lichen pilaris) were present on the nape. These have now practically disappeared.

Microscopical examination revealed characteristic hairs in each subject. They all had pediculosis capitis.

\section{Family History}

There are three other female children of the family who are unaffected. One of them has flaxen hair, the others reddish-brown hair like the colour of that of those affected. In order of age the affected children come first, fourth, and sixth. The father, a bricklayer, is unaffected. His grandfather was employed as a forester on an estate at Stranraer, as also was his father, who was later employed in the same capacity on a Cumnock estate. The mother's father and grandfather were ironworkers at Dalmellington Iron Works. Her mother was the daughter of a weaver. She has a brother, a miner, who lives near to her, who is unaffected, and so are all his children. Her sister and family show no signs of 
monilethrix. The family has never had, on either side, any relative engaged in farming. This $I$ ascertained in making inquiry to exclude the possibility of there being consanguineous relationship with the family reported by the late Professor Sir Thomas McCall Anderson in his Treatise on Diseases of the Skin (second edition, 1894). Nor is the family related to the group of twenty-two cases, including five generations, previously reported by me, of which all the adult males from the first generation had followed the occupation of coal-miner.

\section{Discussion and Conclusion}

Arresting features in this familial and congenital group are:

(a) The mother appears to have been the first member of the family to show signs of the disease. I have failed to get any history of the affection in previous generations, and hei brother and sister are unaffected.

(b) Associated keratosis pilaris tends, as demonstrated in her own case, to disappear with advancing years. To this feature of the disease I made allusion in my earlier report.

(c) Assuming that there was some slight inaccuracy in the mother's statement as to the age when improvement appeared in the case of her older boy, it would seem that in some cases the onset of puberty, a period of increased glandular activity, has a beneficial influence in stimulating the growth of the hair of the scalp; this is certainly shown in the case of a boy in the previous group.

(d) The disease in the girl sent to me by Dr. Howat on August 24th, 1933, had, previously to his having seen her, been diagnosed as tinea tonsurans. Reference to such a diagnostic error having been made was mentioned in my earlier article.

It appears to me exceptional to be able to report a second series of cases after so short an interval, for monilethrix is a rare affection. It is well, therefore, always to bear this condition in mind, especially when examining the scalps of children with respect to fitness for attendance at school.

\section{TREATMENT OF HAMMER-TOE \\ sY}

\section{W. SAYLE CREER, M.B., M.Ch.ОRTh. LIVERPOOL}

In treating this deformity, in either the congenital or the acquired form, several very troublesome complications have been met. They were due in every case to difficulties of splintage after the common operation of wedge excision of the proximal interphalangeal joint. An account of the complications and their causes, with a description of a new splint which eliminated them, may not be without interest to those who use this method of treatment.

\section{Operative Methods}

In a review of the subject Trethowan ${ }^{1}$ mentions four operative methods of curing hammer-toe. The first is to amputate the whole toe, which, while removing the deformity, is a very sweeping operation, though one has yet to learn of a more satisfactory treatment in the case of a deformed little toe, while amputation of the terminal phalanx of the other three smaller toes, if this is the only affected part, gives good results. The great disadvantage of amputation of the whole of any of these toes is that it leaves a gap which the two neighbouring toes attempt to fill in. The alteration of their axes not only adds fresh deformities, but may also give rise to further disability by the production of pain.

The second treatment is to excise the proximal phalanx. Although this filleting leaves a flail-toe, it is probable that very little disability would arise in these days when we seldom appear without the support of a shoe. The method does not, however, conform to the ideals of modern plastic and reconstructive surgery.

In the third method, tenotomy of the tendons and the joint capsule, we have an effective treatment in selected cases. As it is very important that the corrected position be retained until all fear of relapse is past, some form of splintage is necessary. I suggest that the new splint, described later, is the easiest and most comfortable that can be used.

Finally, we have the common operation of interphalangeal arthrodesis by wedge excision of the affected joint, which in the majority of cases will be the proximal joint. After this latter operation a perfect result will leave the proximal interphalangeal joint stiff in almost full extension, and the metatarso-phalangeal and distal joints free from any hyperextension. Such a toe can

${ }^{2}$ Trethowan, W. H.: Lancet, 1925, i, 1257. grip the ground like a normal toe, but must be painless and unable to re-deform. Experience has led many of us to believe that to fulfil these conditions the arthodesis must be bony, for a long fibrous ankylosis is easily strained, with consequent pain, and will not remain extended, while even a short fibrous union re-deforms as the months pass. Now in the full list of causes of failure of consolidation in fractures and arthrodeses there can be no doubt that considerable angular movement occupies a prominent place. In the toe the phalanges are so minute that we often fail to appreciate how much of this type of movement takes place when what appears to be only negligible motion is allowed at the ends distant from the arthrodesis. Its prevention requires an efficient form of splintage.

Use of Splintage

In the past two types of splintage have been used. Of the first, collodion and ribbon gauze, I have no experience in this connexion, but from observation of its use in other conditions-for example, fractures-for which it is excellent, I should be surprised to find it sufficiently strong to retain the corrected position, even if tenotomy is performed at the same time as the wedge excision. Its use also necessitates complete removal-not an entirely painless procedure-when the sutures are removed. I believe that removal of the splintage for even a short time at this period to be detrimental to the rapid and certain attainment of bony fusion.

The second type used is a small wooden or metal splint affixed by means of adhesive tape. Satisfactory fixation had real difficulties. Because of their shape it is no easy matter to attach any straight object either to the dorsal or to the plantar surface of the foot and toe. When applied on the plantar aspect the thick tread of the foot keeps the splint away from good contact with the proximal phalanx, and tends to hyperextend the excised joint. If attached on the dorsal surface, it plantar-flexes the metatarso-phalangeal joint to such an extent that the patient is in great pain for several days. Even with careful padding above and below the dressing over the wound it is difficult to avoid this, while at times the arthrodesis is found later to have been splinted in partial flexion.

The net result has often been a splint that " fits where it touches " without immobilizing, and touches where it should not fit, with resulting malposition. This touching, or rather pressing, where it should not is another source of considerable trouble, particularly when the splint is on the dorsal aspect. 'Despite careful padding the splint presses on the wound through the dressing, frequently causing moisture of the skin edges and delayed healing, 